\title{
Root Surface Defect Produced by Hand Instruments and Ultrasonic Scaler with Different Power Settings: an In Vitro Study
}

\author{
Renato Corrêa Viana CASARIN \\ Fernanda Vieira RIBEIRO \\ Antonio Wilson SALLUM \\ Enilson Antonio SALLUM \\ Francisco Humberto NOCITI-JR \\ Márcio Zaffalon CASATI
}

Department of Periodontics and Prosthodontics, Piracicaba Dental School, State University of Campinas, Piracicaba, SP, Brazil

\begin{abstract}
The aim of this study was to evaluate the root surface defect produced by hand curettes and ultrasonic tips with different power settings. Forty root surfaces were divided into 4 groups according the treatment: Gracey curettes, ultrasonic scaler at $10 \%$ power, ultrasonic scaler at $50 \%$ power and ultrasonic scaler at $100 \%$ power. Each specimen was instrumented with 15 strokes and the and divided in the middle to evaluate: (1) the defect depth produced by the instrumentation and (2) contact area of the instrument tips, which was analyzed by scanning electron microscopy. ANOVA and Tukey's test were used for statistical analysis $(\alpha=0.05)$. The results (mean \pm SD) of the contact area showed significantly greater defects $(p<0.05)$ for the hand instrumented groups $(2092.9 \pm 482)$ compared to the ultrasonic groups $(606.8 \pm 283.0 ; 858.6 \pm 422.5 ; 1212.0 \pm 366.7$, respectively), independently of the power setting. The values for the defect depth on root surface showed no statistically significant difference $(\mathrm{p}<0.05)$ between hand instrumentation $(66.1 \pm 34.0)$ and ultrasonic scaling at $10 \%, 50 \%$ or $100 \%$ power settings $(52.4 \pm 22.1 ; 72.0 \pm 29.9 ; 77.7 \pm 37.7$, respectively). The findings of this study demonstrate that ultrasonic instrumentation produced a similar defect depth to that of hand instrumentation, with a smaller tip contact area, independently of the power setting used for scaling.
\end{abstract}

Key Words: ultrasonics, root scaling, root planing, power.

\section{INTRODUCTION}

The ideal goal of periodontal instrumentation is to effectively remove plaque and calculus without causing root surface damage. Scaling and root planning are the basis of periodontal therapy and various instruments have been designed to achieve this goal. Ultrasonic scaler and curettes are the instruments used for surgical and non-surgical periodontal therapy and have shown similar results as for biological response, plaque/calculus removal and elimination of endotoxin (1). Currently, the use of the ultrasonic scaler has appeared as an important alternative for daily clinical use due to its several advantages, such as access to furcation, less operator tiredness, pocket penetration and less time required for scaling and root planning $(1,2)$. Studies evaluating differences in the magnitude of root surface alterations produced by hand, sonic, and ultrasonic instruments are inconclusive (1-3). Considering manual and ultrasonic scalers, some reports indicate that manual scalers remove more root substance (4), whereas others found that ultrasonic scalers do so (2). At same time, root surface roughness after instrumentation is one of the most described alterations in the literature. The relationship between the tip design, applied force, angulations and type of ultrasonic scaler has been studied and all of these variables have been shown to account for the roughness of instrumented root surfaces (5).

Ribeiro et al. (6) have shown that scaling with diamond-coated sonic and universal ultrasonic tips

Correspondence: Dr. Márcio Zaffalon Casati, Faculdade de odontologia de Piracicaba, UNICAMP, Avenida Limeira, 901, Areião, 13414-903 Piracicaba, SP, Brasil. Tel: +55-019-2106-5301. Fax: +55-19-2106-5301. e-mail: casati@fop.unicamp / brcasati@fop.unicamp.br 
produced similar root surface roughness, which was greater than the that produced by hand curettes. In addition, another study (7) showed a positive influence of the power settings of ultrasonic scaler on the surface roughness after instrumentation. According to those authors, more accentuated roughness was seen with greater power settings. Lie and Leknes (8) evaluated the alterations produced at different power settings using a subjective and controversial method, the Roughness Loss of Tooth Substance Index (RLTSI). The RLTSI evaluates roughness and substance loss concomitantly. However, the loss of tooth substance with the use of a specific instrument cannot be directly correlated with the roughness produced on root surface $(3,9)$, needing a separate evaluation (9).

Regarding the objective and reproducible quantification of aggressiveness, i.e., loss of tooth substance by an instrument, such an evaluation has been approached in several manners. The loss of tooth substance has been estimated, for example, by determining the integral calculation of the area under the curve of profilometric curves (5) and has been subjectively quantified by the analysis of scanning electron microscopy (SEM) micrographs of the specimens by means of well-defined index systems (8). However, a standard method for the in vitro investigation of the so-called aggressiveness to tooth substance has not yet been established, due the difficulty in affirming which method is more acceptable or real.

Although several studies have described the topography and roughness after different types of instrumentation $(6,7)$, the influence of power settings on tooth loss removal during ultrasonic instrumentation remains unknown. Therefore, the aim of this standardized in vitro study was to evaluate tooth substance loss after hand and ultrasonic instrumentation with different power settings.

\section{MATERIAL AND METHODS}

\section{Tooth Selection and Mounting Procedures}

The research protocol was reviewed and approved by the local Research Ethics Committee under protocol number 02/2006.

Forty mandibular and maxillary premolars extracted for orthodontic reasons were selected for this study. All teeth were donated to the study and were rinsed in $10 \%$ formalin solution for 1 month. All teeth had to meet the following criteria to be used: intact root surface, absence of caries, no previous periodontal involvement, absence of gross soft and hard debris. The final selection was made with a $\times 4$ stereomicroscope magnification. Teeth with root concavities or convexities that impeded root planing were excluded.

The teeth were decoronated and each root was mounted in a 2-cm-high plastic tube filled with acrylic resin (Jet; Clássico Artigos Odontológicos Ltda., São Paulo, SP, Brazil), keeping exposed the most plane surface between the buccal or lingual surface. Before instrumentation, the roots were polished with rotating sandpapers of decreasing abrasiveness (\#300, \#400, \#600 and \#1200) and felt discs until reaching a similar visual roughness for all specimens. The mounted teeth were numbered 1 to 40 and randomly assigned by coin toss to one of the 4 study groups. To avoid reading localization errors, a $3 \times 3 \mathrm{~mm}$ area at the polished face of each root was delimitated as the reading area.

\section{Root Scaling}

Four treatment modalities were performed by the same operator: scaling with Gracey curettes 5-6 (Gracey; Hu-Friedy, Chicago, IL, USA) and scaling with ultrasonic scaler (Dabi Profi III; Bios, Ribeirão Preto, SP, Brazil) at low power $(10 \%)$, medium power $(50 \%)$ or high power $(100 \%)$. The group treated with curettes received 15 apical to coronal strokes with a new curette for each tooth. The ultrasonic groups received 15 apical to coronal strokes with a zero degree inclination between the tip and root (5).

\section{Analysis of Tooth Substance Loss}

In each tooth, the midline was determined and a 2-mm-thick slice of this area was cut. The slices were dehydrated in acetone, dried in an incubator for $12 \mathrm{~h}$, fixed on stubs with the scaled surface faced upwards and sputter-coated with gold for analysis with a scanning electron microscope (JEOL JSM-T330A; JEOL Ltd, Tokyo, Japan). Two parameters were measured by a calibrated examiner using a JEOL software: Defect depth promoted by different instruments (the distance of the deepest point to the specimen margin); and the contact area of the instruments on the root surface (the distance of the largest points of the scaled area) (Fig. 1). Ten teeth not used in the study were previously selected 
for examiner calibration. The examiner evaluated the study parameters in all teeth twice within $24 \mathrm{~h}$. Intraclass correlation was calculated for each parameter, resulting in $85 \%$ reproducibility for defect depth and $84 \%$ for contact area. After root scaling, each specimen received a code to blind the examiner during the analysis in order to avoid methodological biases. The code was revealed only at the moment of statistical analysis.

\section{Statistical Analysis}

The sample size was determined using Bioestat 4.0 statistical software. A total of 10 teeth per group were chosen considering $15 \mu \mathrm{m}$ of difference between groups in defect depth and $10 \mu \mathrm{m}$ of standard deviation. Regarding the contact area, 10 teeth were sufficient to determine a difference of $600 \mu \mathrm{m}(\mathrm{SD}=300 \mu \mathrm{m})$. All tests considered a $\alpha=0.05$ and a $\beta$-error $=0.8$.

Differences in the defect depth promoted by both instrumentation techniques as well as in the contact area of the instruments on the root surface means after instrumentation were evaluated by ANOVA. As the Shapiro-Wilk test showed normal data distribution, the Tukey's test was used to identify the differences among the groups. A 5\% significance level was set for analyses.

\section{RESULTS}

The values of defect depth and contact area are shown in Table 1. The power setting of the ultrasonic scaler did not influence the defect depth on root surface $(p>0.05)$. The values obtained with the hand curettes did not differ from those obtained with the ultrasonic scaling, independently of the power setting used ( $p>0.05$ ).

The contact area of the instrument with the root surface showed the highest mean value with hand instrumentation $(p<0.05)$ (Fig. 2) when compared to the ultrasonic scaling (Figs. 3-5). No statistically significant differences ( $p>0.05)$ were observed among the groups regarding the power settings of the ultrasonic scaler.

\section{DISCUSSION}

For several decades, the objective of periodontal instrumentation was to remove plaque, calculus, endotoxins and contaminated cementum by a vigorous scaling of the root surface. Endotoxins are superficially associated with cementum, dentin and calculus and are easily removed with brushing, polishing, washing and slight scaling (10). Maintenance of cementum and healthy dentin showed important results in histological and clinical studies, and extensive cementum and dentin removal appears to be not necessary to achieve efficient healing (10). Thus, following confirmation that different scaling instruments all achieve efficient tooth substance removal, the choice of the least aggressive instrument appears to be necessary.

In the present study, linear measurements of defect depth and contact area of the instrument appeared after scaling and root planing were evaluated to determine the tooth substance loss during the instrumentation. The hand instrumentation showed similar defect depth to that produced by the ultrasonic scaler. In a SEM evaluation, Vastardis et al. (12) did not find any difference between these two forms of root instrumentation with regard to the defect depth, although other studies have reported less root substance removal by ultrasonic scalers compared to hand instruments $(1,4)$. However, in a recent study, the piezoelectric scalers removed less root substance than hand curettes (13). These studies, however, did not determine the influence of the power setting in the aggressiveness to the root surface.

At minimum power setting, the defect depth promoted by the ultrasonic scaler was $52.4 \pm 22.1 \mu \mathrm{m}$ and, at maximum power setting, $77.7 \pm 37.7 \mu \mathrm{m}$. The different power settings did not have any significant influence on the defect depth, producing defects with similar depths as those reported by other authors $(14,15)$. However, comparisons to other studies should be done with caution. Different methodologies could led to divergent conclusions, since the type of evaluation (profilometer, laser Doppler or SEM evaluation) and the determination of the analysis area (3) have been shown to directly affect the results. In the present study, care was taken to maintain the standardization of the specimen

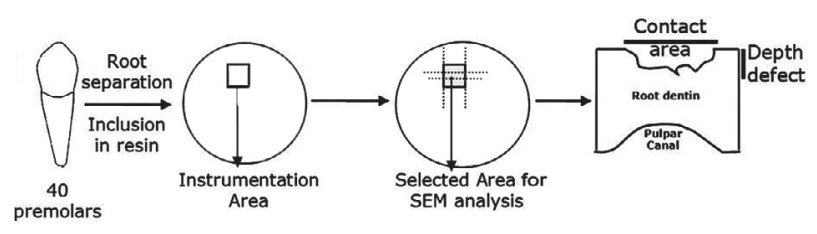

Figure 1. Delineation of specimen preparation. After root separation and inclusion, root surface was instrumented in a determined area. The central portion of this area was selected to determine the contact area and defect depth under SEM. 
evaluation. The previous selection of the instrumentation area, polishing and specific SEM measurements reduce the influence of the external variables, highlighting the findings of the study.

Nevertheless, although the methodology of the present study hinders the comparison of calculus removal potential of hand and ultrasonic instruments, it has been investigated by several authors. Oda et al. (2), in a literature review, has shown the contradictory findings of in vitro studies regarding calculus removal, mainly because of the strong differences in methodology and study designs. However, another literature review (1) concluded that manual and power-driven scaler (ultrasonics ad sonics) are equally effective in calculus removal, though these technique present different levels of tooth removal substance.

Walmsley et al. (15) reported an erosive activity due to the acoustic microstreaming of the ultrasonic scaler that preferentially removed the harder brittle inorganic constituents of dentin and cementum, leaving behind the softer organic structures. According to the authors, the analysis of SEM micrographs showed thatt hese valleys formed by the ultrasonic instrumentation gave the surface a rougher aspect, with several grooves
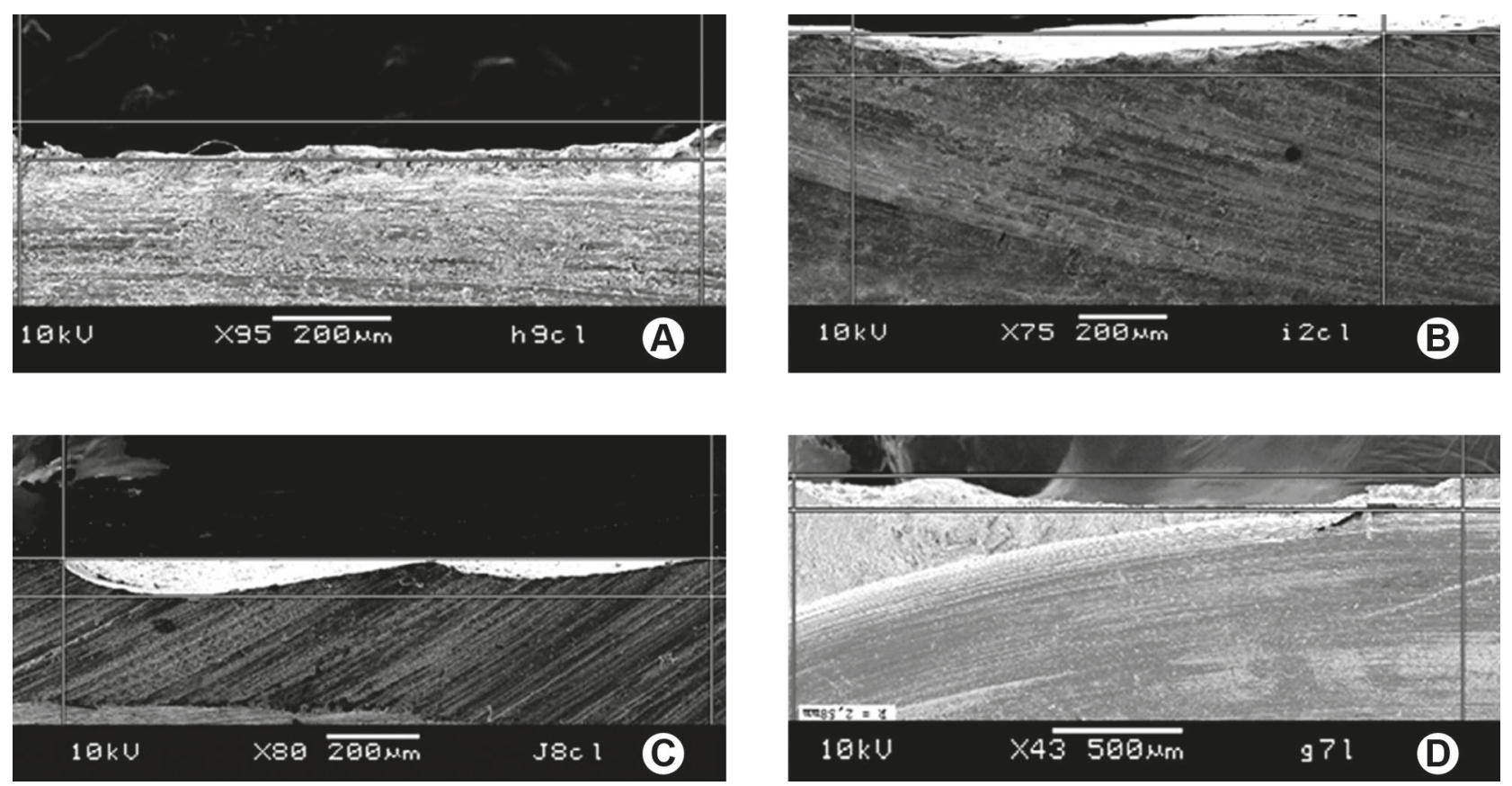

Figures 2. SEM micrographs of root surface treated by hand curettes (A) and ultrasonic scaler at low (B), medium (C) and high (D) power setting, respectively. Note the defect produced by these forms of root instrumentation and the greater contact area between root surface and the Gracey curette. The images show similar defects produced by the 3 power settings of the ultrasonic scaler. and gouges on root surface. Another explanation for the abrasive capacity of the ultrasonic scaler is the occurrence of burns and hamp on root surface (16), and the fast oscillatory movements of the tip that wear out more root substance leading to the formation of longer and deeper defects and a rougher surface (16). The Gracey curettes and other manual instruments remove several layers of root substance and are intimately dependent on the applied force, angle and sharpness of the curette tip (5). This abrasive activity is graphically represented in Figure 1, where the surface presents a deep defect in the topography.

The values obtained in this study for the contact area of the instruments with the root surface after scaling and root planning show that hand instruments present a significantly greater contact area between the instrument and the root surface than that of ultrasonic instruments $(p<0.05)$, regardless of the power setting used. A greater contact area could result in a smoother surface, masking the valleys formed on root surface due to root substance removal. This result may explain or confirm the influence of the tip on the root topography after instrumentation, since the ultrasonic power setting did not influence the contact area. 
Regardless of the instrument used for scaling and root planing treatment, root surface presented valleys and sulcus (Fig. 2 to 5). The denudation of root dentin, due to removal of cementum and dentin layers, is another complication in scaling procedure (17). A large number of dentinal tubules are exposed, leaving direct pathways to the pulp for bacteria and bacterial byproducts present in the oral environment (18). Increased dentin sensitivity may also result from tubule exposure, causing hydrodynamic stimulation (19).

Another interesting aspect to be considered is the direct influence of the topography on healing after the instrumentation of diseased roots. Since several sulci and valleys were formed after instrumentation, an increase in the roughness also is observed (6-8). Some authors have discussed the negative influence of supragingival roughness on biofilm formation and mechanical plaque control by the patient (2). A literature review (20) concluded that the defects on root surface are protected against the removal forces, increase the difficult in performing oral hygiene. This favors biofilm adherence, retention and maturation. However, the influence of the subgingival root surface is still undetermined in the literature and further research is needed to investigate whether root surface anatomy after scaling and root planing could affect negeatively the success of periodontal treatment.

With regard to the unnecessary extensive removal of root substance to achieve periodontal healing (10) and the adverse reactions produced by this procedure, caution should be exercised when scaling subgingival areas because the retraction of the inflammed gingival tissue expected after scaling and root planing could lead subgingival areas to become become supragingival.

Within the limitations of this in vitro study, it may be concluded that ultrasonic instrumentation produced a similar defect depth to that of hand instrumentation, with a smaller contact area between the instrument and the root surface, independently of the power setting used for scaling.

\section{RESUMO}

O objetivo deste estudo foi avaliar o defeito na superfície radicular produzido por curetas manuais e instrumento ultra-sônico em diferentes potências. Quarenta superfícies radiculares foram divididas de acordo com o tratamento em 4 grupos: a) Curetas Gracey; b) Instrumento ultra-sônico a 10\%; c) Instrumento ultra-sônico a $50 \%$; d) Instrumento ultra-sônico a 100\%. Cada amostra recebeu 15 movimentos de raspagem e foram divididas ao meio para avaliar: (1) a profundidade do defeito produzido pela instrumentação e (2) a área de contato do instrumento com a superfície. Todas as superfícies foram então avaliadas com o uso de Microscopia Eletrônica de Varredura. Para a análise estatística foi utilizado o teste Tukey/ANOVA. Os resultados (média \pm DP) encontrados para a área de contato foram significantemente maiores para a instrumentação manual $(2092,9 \pm 482,0)$ que para os instrumentos ultra-sônicos, independentemente da potência utilizada $(606,8 \pm$ 283,$0 ; 858,6 \pm 422,5 ; 1212,0 \pm 366,7$, respectivamente). Os valores para a profundidade do defeito demonstraram numericamente, mas não estatisticamente, diferenças entre a instrumentação manual $(66,1 \pm 34,0)$ e ultra-sônica em $10 \%, 50 \%$ ou $100 \%$ de potência $(52,4 \pm 22,1 ; 72,0 \pm 29,9 ; 77,7 \pm 37,7$, respectivamente). Os resultados encontrados demonstraram que a instrumentação ultra-sônica produziu defeitos com profundidade similar aos produzidos pela instrumentação manual, com um menor contato do instrumento, independente da potência utilizada.

\section{ACKNOWLEDGEMENTS}

The authors would like to thank the São Paulo State Research Foundation (FAPESP) for the financial support to this study (Grant 02/00666-1).

\section{REFERENCES}

1. Walmsley AD, Lea SC, Landini G, Moses AJ. Advances in power driven pocket/root instrumentation. J Clin Periodontol 2008;35:22-28.

2. Oda S, Nitta H, Setoguchi T, Izumi Y, Ishikawa I. Current concepts and advances in manual and power-driven instrumentation. Periodontol 2000 2004;36:45-58.

3. Kocher T, Langenbeck N, Rosin M, Benhardt O. Methodology of three-dimensional determination of root surface roughness. J Periodontal Res 2002;37:125-131

4. Jacobson L, Blomlof J, Lindskog S. Root surface texture after different scaling modalities. Scand J Dent Res 1994;102:156-160.

5. Flemmig TF, Petersilka GJ, Mehl A, Hickel R, Klaiber B. The effect of working parameters on root substance removal using a piezoelectric ultrasonic scaler in vitro. J Clin Periodontol 1998;25:158-163.

6. Ribeiro FV, Casarin RCV, Nociti-JR FH, Sallum EA, Sallum AW, Casati MZ. Comparative in vitro study of root roughness after instrumentation with ultrasonic and diamond tip sonic scaler. J Appl Oral Sci 2006;14:124-129.

7. Casarin RCV, Pinto FR, Sallum AW, Sallum EA, Nociti-Jr FH, Casati MZ. Assessment of ultrasonic root surface scaling with different power settings. Roughness evaluation. Braz Journal of Oral Sci 2006;17:996-1000.

8. Lie T, Leknes KN. Evaluation of the effect on root surfaces of air turbine scalers and ultrasonic instrumentation. J Periodontol 1985;56:522-531.

9. Schmidlin PR, Beuchat M, Busslinger A, Lehmann B, Lutz F. Tooth substance loss resulting from mechanical, sonic and ultrasonic root instrumentation assessed by liquid scintillation. J Clin Periodontol 2001;28:1058-1066.

10. Nyman S, Westfelt E, Sarhed G, Karring T. Role of “diseased” root cementum in healing following treatment of periodontal disease. A clinical study. J Clin Periodontol 1988;15:464-468.

11. Smart GJ, Wilson M, Davies EH, Kieser JB. The assessment of ultrasonic root surface debridement by determination of residual 
endotoxin levels. J Clin Periodontol 1990;17:174-178.

12. Vastardis S, Yukna RA, Rice DA, Mercante D. Root surface removal and resultant surface texture with diamond-coated ultrasonic inserts: an in vitro and SEM study. J Clin Periodontol 2005;32:467-473.

13. Kawashima H, Sato S, Kishida M, Ito K. A comparison of root surface instrumentation using two piezoelectric ultrasonic scalers and a hand scaler in vivo. J Periodontal Res 2007;42:90-95.

14. Rosenberg RM, Ash MM Jr. The effect of root roughness on plaque accumulation and gingival inflammation. J Periodontol 1974;45:146-150.

15. Walmsley AD, Walsh TF, Laird WR, Williams AR. Effects of cavitational activity on the root surface of teeth during ultrasonic scaling. J Clin Periodontol 1990;17:306-312.

16. Yukna RA, Vastardis S, Mayer ET. Calculus removal with diamond-coated ultrasonic inserts in vitro. J Periodontol 2007;78:122-126.
17. Coldiron NB, Yukna RA, Weir J, Caudill RF. A quantitative study of cementum removal with hand curettes. J Periodontol 1990;61:293-299.

18. Bergenholtz G, Lindhe J. Effect of experimentally induced marginal periodontitis and periodontal scaling on the dental pulp. J Clin Periodontol 1978;5:59-73.

19. von Troil B, Needleman I, Sanz MJ. A systematic review of the prevalence of root sensitivity following periodontal therapy. J Clin Periodontol 2002;29 Suppl 3:173-177,discussion 195-196.

20. Teughels W, Van Assche N, Sliepen I, Quirynen M. Effect of material characteristics and/or surface topography on biofilm development. Clin Oral Implants Res 2006:17 Suppl 2:68-81.

Accepted February 1, 2009 